\title{
ANÁLISE DAS INTERAÇÕES E DAS MEDIAÇÕES DE PROFESSORES DE MATEMÁTICA DURANTE UMA PROPOSTA DE FORMAÇÃO CONTINUADA
}

\author{
ANALYSIS OF MATHEMATIC TEACHER INTERACTIONS AND MEDIATIONS DURING A CONTINUING \\ TRAINING PROPOSAL \\ Adriana Fátima de Souza Miolaํㅗ Patrícia Sandalo Pereira²
}

\section{RESUMO}

Este artigo tem como objetivo apresentar as interações e as mediações que ocorreram em uma proposta de formação continuada desenvolvida por meio da metodologia da pesquisa colaborativa durante uma pesquisa de doutorado. O estudo utilizou a pesquisa colaborativa, segundo Ibiapina, como metodologia, sendo essa uma modalidade de pesquisa que se encontra ancorada na Abordagem Histórico Cultural de Vygotsky, em que a sua premissa é conhecer a essência do fenômeno por meio de seu processo histórico real e de seu desenvolvimento, em que o sujeito é considerado parte inerente à sociedade da qual faz parte. Os dados desta pesquisa foram produzidos entre $2013 \mathrm{e}$ 2016 no projeto OBEDUC, núcleo UFMS, a partir de 38 sessões, uma entrevista coletiva e envolveu dois professores de matemática. Os dados foram analisados por meio de dois eixos temáticos; Mediação e Colaboração. Como resultado, destacamos que a formação realizada no estudo, por meio da metodologia da pesquisa colaborativa, mostrou-se uma oportunidade também de pesquisa para todos os participantes, propiciou coprodução de saberes, possibilidade de reflexão crítica e de colaboração. O formato de formação criou vínculo e foi além das produções que gerou, foi uma abordagem de formação contínua, que atingiu a vontade do professor de ser pesquisador, e de cruzar os caminhos da universidade e da escola.

PALAVRAS-CHAVE: Formação de Professores. Pesquisa Colaborativa. Colaboração.

\section{ABSTRACT}

This article aims to present the interactions and mediations that occurred in a proposal of continuous training developed through the collaborative research methodology during a doctoral research. The study used collaborative research, according to Ibiapina, as a methodology, being a research modality that is anchored in the Cultural Historical Approach of Vygotsky, in which its premise is to know the essence of the phenomenon through its real historical process and its development, in which the subject is considered an inherent part of the society of which he is a part. The data of this research were produced between 2013 and 2016 in the OBEDUC project, UFMS centre, from 38 sessions, a press conference and involved two teachers of mathematics. The data were analyzed through two thematic axes; Mediation and Collaboration. As a result, we emphasize that the training conducted in the study, through the methodology of collaborative research, was also an opportunity for research for all participants, provided coproduction of knowledge, possibility of critical reflection and collaboration. The training format created a link and went beyond the productions it generated; it was an ongoing training approach that reached the teacher's desire to be a researcher, and to cross the journey of the university and the school.

KEYWORDS: Teacher Training. Collaborative Research. Collaboration.

\footnotetext{
1 Doutora em Educação Matemática pela Universidade Federal de Mato Grosso do Sul (UFMS). Docente da Universidade Federal da Grande Dourados (UFGD). Integrante do Grupo de Pesquisa FORMEM - Formação e Educação Matemática. E-mail: drica220@yahoo.com.br

2 Doutora em Educação Matemática pela UNESP - Rio Claro. Diretora do Instituto de Matemática e Docente da Universidade Federal de Mato Grosso do Sul (UFMS). Líder do Grupo de Pesquisa FORMEM - Formação e Educação Matemática. E-mail: sandalo.patricia13@gmail.com
} 


\section{FORMAÇÃO CONTINUADA DE PROFESSORES DE MATEMÁTICA: DE ONDE VIEMOS E PARA ONDE IREMOS}

A formação continuada de professores tem como um de seus objetivos aperfeiçoar a prática pedagógica dos professores para as mudanças que ocorrem no meio educacional. Com isso, buscamos leituras sobre essa temática para entender como a formação vem sendo compreendida e quais mudanças ocorreram ao longo das últimas décadas.

A seguir, faremos um breve posicionamento sobre a temática, com o propósito de compreender quais as bases iniciais do assunto, em que situação se encontra, para que possamos apontar para onde iremos com a proposta de formação continuada abordada nesta pesquisa. Para isso, recorremos a autores como Imbernón (2009, 2010), para situar a formação continuada, ou seja, para compreendermos como surgiu e quais as perspectivas atuais desse termo.

Para o autor, a formação continuada de professores começou a institucionalizar-se em alguns países, a partir dos anos de 1970, com a intenção de adaptar os professores à sua contemporaneidade. Até então, as formações propostas eram autoritárias, classistas, uniformizadoras e seletivas, predominando um modelo individual de formação.

$\mathrm{Na}$ década de 1980, a necessidade de uma formação diferenciada daquela vivida até então levou as universidades a criar programas de formação continuada de professores em modalidades de treinamentos e de práticas, como, por exemplo, programas de minicursos, análise de competências técnicas, entre outros. Naquela década, o paradigma da racionalidade técnica e autoritarismo avançaram sem alternativa e a busca pela competência e pelo bom professor tornou-se o principal tópico de pesquisa na formação continuada.

Os cursos padronizados oferecidos pelas instituições baseavam-se em um formador, que apresentava atividades que deveriam ajudar os professores a atingir os resultados. Embora esse modelo não funcionasse em muitos países, resistiu por muito tempo e ainda perdura em algumas formações continuadas. No período dos anos de 1990, entretanto, começaram as preocupações sobre estudos teóricos e modelos al- ternativos de formações no âmbito das universidades, com o aparecimento de textos, comunicações, experiências, eventos, entre outros.

Naquele período, ocorreram dois movimentos, um por meio das pressões do mundo do trabalho, que vinha se estruturando e exigindo um modelo informatizado, e outro, que constatava os precários desempenhos escolares de grande parte da população. Com isso, uma movimentação de políticas públicas e ações políticas ocorreram em direção de reformas curriculares e de mudanças na formação dos docentes.

Freitas (2002) reforça essa discussão ao apresentar que, no âmbito da formação continuada, as políticas têm reforçado uma concepção pragmatista e conteudista e que o art. 87, § $4^{\circ}$ da LDB n 9.394/ 96, que estabelece que: "Até o fim da Década da Educação somente serão admitidos professores habilitados em nível superior ou formados por treinamento em serviço", tem levado muitos professores a frequentar cursos de qualidade duvidosa.

Com todos esses momentos vividos pela formação continuada, a partir do início do século XXI, surgiram propostas de formação e novos modelos de programas vinculados à prática da formação de professores que ganharam espaço. Atualmente, não se analisa mais a formação somente como domínio de conteúdo, mas o que se aprende e o que falta aprender, conforme Imbernón (2010).

Dentre os vários sentidos e significados atribuídos à formação continuada ao longo do tempo, destacam-se também: treinamento, qualificação, aperfeiçoamento, aprimoramento, capacitação e outros. Entretanto, essas compreensões esforçam-se na busca de intervenções que possam melhorar o processo de ensino e aprendizagem docente.

Desse modo, busca-se um trabalho de formação continuada de caráter coletivo, na perspectiva colaborativa, em que os participantes podem refletir em equipe e buscar juntos soluções para as situações-problema do cotidiano da sala de aula e tentar abandonar o caráter individualista atribuído à atuação docente há algumas décadas passadas. A partir disso, compreendemos ser necessário desenvolver na formação continuada atividades que proporcionem interação e mediações que possibilitem a colaboração, a reflexão crítica e o desenvolvimento profissional 
dos participantes por meio de um trabalho colaborativo, a fim de buscar soluções para os problemas do cotidiano escolar.

A partir dessa perspectiva teórica, compreendemos que a formação continuada não deve apenas incluir os professores em seus processos formativos, mas construir condições objetivas que viabilizem a constituição de um coletivo que admita as suas necessidades e transformem-nas em atividades formativas, potencializadoras de seu desenvolvimento profissional docente.

\section{1 - A FORMAÇÃO CONTINUADA DE PROFESSORES COMO ATIVIDADE}

Compreendemos formação continuada, segundo a perspectiva teórico-metodológica da atividade, a qual tem como principais conceitos: estrutura da atividade, atividade dominante, significado social e sentido pessoal. Segundo Leontiev (1978), a estrutura da atividade é constituída por: necessidade, motivo, operação, ação, condições e objeto. A necessidade é considerada indispensável a qualquer atividade.

A primeira condição de toda a atividade é uma necessidade. Todavia, em si, a necessidade não pode determinar a orientação concreta de uma atividade, pois é apenas no objeto da atividade que ela encontra sua determinação: deve, por assim dizer, encontrar-se nele. Uma vez que a necessidade encontra a sua determinação no objecto (se "objectiva" nele), o dito objecto torna-se motivo da atividade, aquilo que o estimula (LEONTIEV, 1978, p. 107-108).

Assim, a necessidade realiza-se no objeto da ação, quando se objetiva nele. Um sujeito articula necessidade e objeto, quando ele busca satisfazer uma necessidade por meio do motivo, com isso, compreendemos uma estreita relação entre necessidade, motivo, objeto e condições, presentes na estrutura da atividade.

O motivo é o que leva o indivíduo a um determinado comportamento, é ele que move a ação e que está diretamente relacionado a uma necessidade que se idealiza. Todavia, para objetivar essas necessidades, o indivíduo depende das condições e do modo como essas ações são realizadas, pois uma mesma ação pode realizar-se por diferentes operações. As- sim, a ação é determinada pelo seu fim e as operações dependem da forma como essas necessidades são satisfeitas.

Quando a necessidade, que foi estimulada pelo motivo, é objetivada no objeto, é dito que essa relação pode ser capaz de conferir significado à ação e ter sentido para quem a realizou. Dessa forma, uma formação continuada não dá significado ao motivo por si só, mas o motivo que se exprime nos fins, em outras palavras, é o sentido que se expressa nas significações.

Sentido e significado possuem relação na estrutura da atividade. Para Leontiev (1978), uma ação constitui atividade somente quando o motivo que levou o indivíduo a agir diz respeito ao conteúdo da ação. Em suas palavras: "os processos que são psicologicamente determinados pelo fato de aquilo para que tendem no seu conjunto (o seu objeto) coincidir sempre com o elemento objetivo que incita o paciente a uma dada atividade, isto é, com o motivo" (LEONTIEV 1978, p. 315).

Desse modo, uma ação só se constitui uma atividade quando o motivo corresponde ao conteúdo da ação. Segundo Duarte (2005, p. 36), "ao conteúdo da ação, isto é, àquilo que constitui seu objeto, vincula-se o significado da ação, ou seja, o significado da ação é aquilo que o sujeito faz". Em outras palavras, quando o objeto, a finalidade do ato, coincidir com o elemento objetivo que incita alguém a agir, o motivo.

Nesse sentido, muitos programas de formação continuada que os professores participam, muitas vezes, são desenvolvidos dissociados do conteúdo de sua atividade docente, visando receber como troca aumento no salário, ascensão na carreira, sobrepondo-se ao interesse de desenvolvimento humano, tanto pessoal quanto profissional.

Nessa perspectiva teórica, a relação social construída por meio da linguagem e do trabalho entre os homens permite a apropriação das significações sociais. Diante disso, o significado social da formação continuada de professores só será apreendido se produzir um sentido pessoal para os envolvidos, se houver uma relação com o seu trabalho, a partir de uma necessidade, e se houver um motivo que estimule essa apropriação. A ação de formação continuada terá um significado social se houver ligação com o trabalho que o professor executa. 
Entendemos que os professores não podem apenas reproduzir o que está determinado e a formação continuada é um espaço em que eles podem compreender a sua historicidade e intervir nela. A formação continuada de professores deve superar o distanciamento entre o significado social e sentido pessoal, entre outros termos. Superar essas e outras resistências implica construir condições objetivas que possibilitem a constituição de coletivos colaborativos que transformem as suas necessidades em atividades formativas.

Uma proposta que trabalha nessa vertente é a formação continuada com fundamentos teórico-metodológicos da pesquisa colaborativa. Essa proposta foi desenvolvida durante a formação continuada realizada no projeto em rede OBEDUC no Núcleo UFMS (2013-2016), que se configurou como o contexto de uma pesquisa de doutorado, desenvolvida entre 2015 e 2018. Essa formação foi a atividade que propiciou as interações e as mediações que podem ter proporcionado o desenvolvimento profissional dos professores de Matemática participantes da presente investigação.

\section{2 - ASPECTOS METODOLÓGICOS DO ESTUDO}

A formação continuada que gerou os dados para esta investigação estava atrelada ao projeto em rede intitulado "Trabalho colaborativo com professores que ensinam Matemática na Educação Básica em escolas públicas das regiões Nordeste e Centro-Oeste", vinculado ao Programa Observatório da Educação (OBEDUC). O projeto no qual realizamos nossa investigação teve a Universidade Federal de Mato Grosso do Sul (UFMS) como instituição sede. Contou com a participação da Universidade Estadual da Paraíba (UEPB) e a Universidade Federal de Alagoas (UFAL). O Núcleo UFMS era composto por uma coordenadora institucional, quatro mestrandos em Educação Matemática, quatro licenciandos em Matemática da UFMS e oito professores da Educação Básica da rede pública de Campo Grande. Neste trabalho apresentamos as interações de dois professores da Educação Básica que chamamos ficticiamente de Lorenzo e Valentina.

A opção por desenvolver esta pesquisa utilizando os dados do projeto OBEDUC, que se desenvolveu na perspectiva da colaboração, justifica-se, pois, a pesquisa colaborativa é uma metodologia que "alia investigação e formação em processos de compreensão, interpretação e transformação de realidades sociais" (IBIAPINA, 2008 p. 11). Por isso, essa perspectiva é considerada, por Ibiapina (2008), como uma via de mão dupla.

Essa abordagem está fundamentada no referencial teórico e metodológico da Teoria Histórico-Cultural e trata de uma modalidade de pesquisa voltada para o desenvolvimento e empoderamento profissional de professores e pesquisadores simultaneamente. Nessa abordagem, o pesquisador exerce a função de formador quando atende as necessidades dos professores, como também a dificuldade de aprendizagem dos alunos e ainda quando apoia os professores iniciantes.

Outra ambiguidade apontada por Desgagné (2007) na investigação colaborativa é a participação que se espera dos integrantes. Por se tratar de pesquisa colaborativa, subentende que todos deverão participar de todas as etapas formais da pesquisa. Entretanto, os participantes não são excluídos das etapas formais da pesquisa, como definição de objeto, coleta de dados, análise e publicação, mas esse tipo de investigação, não exige que os docentes participem como co-pesquisadores.

Entretanto, eles podem ter como objetivo a formação para pesquisa se considerarem isso indispensável para o seu desenvolvimento profissional. A verdadeira contribuição docente está na sua participação como co-construtores do projeto de investigação. Para Desgagné (2007), colaborar é cada participante oferecer a sua contribuição específica, beneficiando todo o conjunto.

Apresentamos na figura 1, algumas características da pesquisa colaborativa que se fizeram presentes no desenvolvimento do estudo que resultou os dados deste trabalho. 


\section{FIGURA - CARACTERÍSTICAS DA PESQUISA COLABORATIVA}

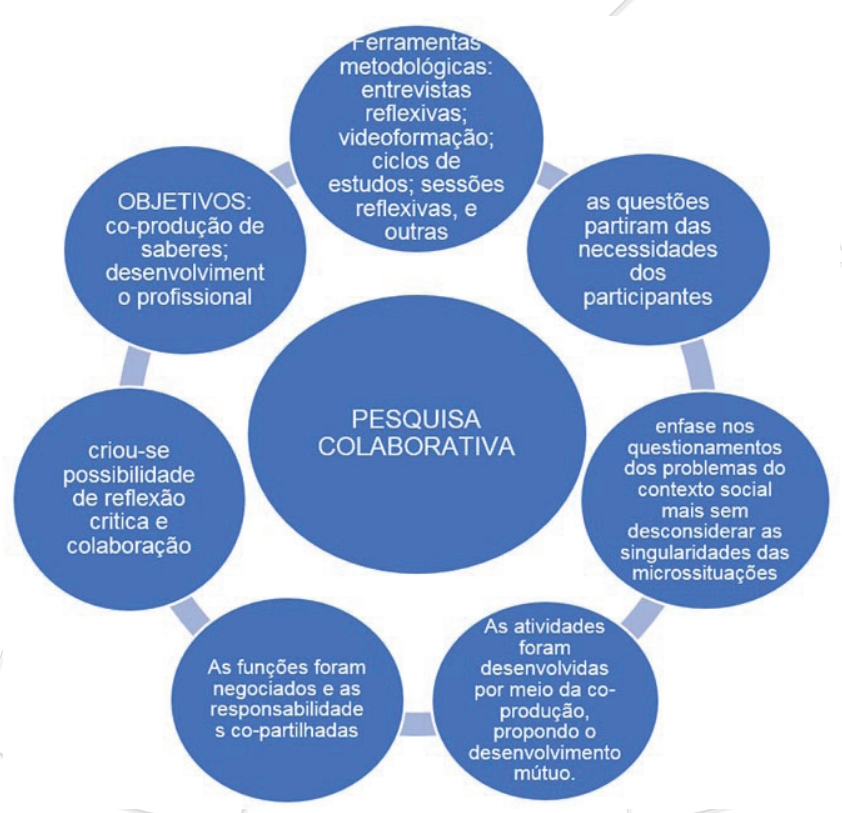

Fonte: Ibiapina (2008)

Para desenvolver a proposta de formação continuada, no contexto desta pesquisa, o grupo discutiu e negociou conjuntamente, levantaram-se as necessidades dos participantes que destacaram pontos relevantes pertencentes às suas práticas. O grupo conheceu o referencial teórico-metodológico, por meio de estudos de textos em que foi planejado o trabalho de campo, como também foram definidos os cronogramas para a realização das sessões; discutiram-se as contribuições de cada participante do grupo, conforme diálogo nas sessões que iniciaram o ano de 2014, momento em que o grupo começou as ações nas escolas. Durante a realização da formação, foram planejados conjuntamente, desenvolvidos e depois discutidos, de forma colaborativa, vários planos de aula, atendendo as necessidades dos participantes.

Das ferramentas da pesquisa colaborativa, foi utilizada, durante as sessões do projeto, a vídeo gravação, além de uma entrevista coletiva, que contribuiu como dados desta investigação. Todas essas ferramentas metodológicas mostraram-se como oportunidades para que os professores visualizassem as suas atuações, realizando uma reflexão crítica inter e intrapsicológica, confrontando teoria e prática. Para desenvolver a proposta de formação continuada, foram dispostos alguns procedimentos metodológicos que produziram os dados do nosso objeto de estudo, que favoreceu o processo de mediação e colaboração no grupo.

Selecionamos instrumentos metodológicos que possibilitassem aos participantes compreenderem que teoria e prática (real e ideal) são elementos que não podem dissociar-se, por isso, devemos sempre discutir e analisá-los, almejando uma prática transformadora. Diante dessa compreensão, utilizamos as sessões realizadas na produção dos dados durante os anos de 2013, 2014 e 2015, e classificamos em sessões colaborativas e sessões reflexivas, como também a entrevista coletiva realizada em março de 2016 com os todos os participantes.

Identificamos como as sessões colaborativas, os encontros que foram realizados em que ocorreram as negociações, os estudos sobre as metodologias desenvolvidas, as leituras reflexivas, os compartilhamentos de experiências entre os participantes e elaboração de plano de aulas. Por meio da entrevista coletiva realizada no final da formação, identificamos momentos de interação e colaboração durante a proposta da formação continuada. Já nas sessões identificadas como sessões reflexivas, buscamos compreender as interações, identificar e classificar as mediações realizadas pelos professores no contexto da formação.

As sessões reflexivas foram desenvolvidas por meio das ações reflexivas utilizadas na vídeoformação e foram desencadeadas por meio de quatro etapas: descrição, informação, confronto e reconstrução. $\mathrm{Na}$ descrição, o professor detalha a sua prática, justificando as suas escolhas por meio de questões do tipo: O que fiz?

A ação de informação leva o professor a refletir sobre as suas escolhas e compreender o seu agir, as razões pelas quais os alunos não aprendem. Essas informações podem ser levantadas por meio de questões como: O que motiva a realizar essas ações? O que significa agir desse modo? O que o leva a agir desse modo? Qual o sentido dessas ações? De onde procedem historicamente essas ideias e como ocorreu a apropriação delas? Por que são utilizadas? entre outras.

A ação de confrontar é o momento principal da reflexão crítica, afirmam Ibiapina e Araújo (2008), pois permite que o professor compreenda o significado de sua prática para mantê-la ou transformá-la. As prin- 
cipais questões nessa ação são: Como cheguei a ser assim? Qual a função social da aula nesse contexto? Qual a função das escolhas feitas na construção da cidadania?, entre outras.

Para as ações de reconstrução é preciso refletir sobre algumas questões, sendo elas: Como posso agir diferente? Como posso mudar minha prática e fazer diferente?, entre outras. Nessa perspectiva, o pesquisador colabora auxiliando o grupo e o grupo auxiliando os colegas a refletirem sobre as suas práticas. Para a compreensão desses momentos e sua condução, apresentamos, na Figura 2, o Ciclo Reflexivo produzido com base em estudos de Liberali (2010), ressaltamos, porém, que esse ciclo não é hierárquico.

FIGURA 2 - CICLO REFLEXIVO

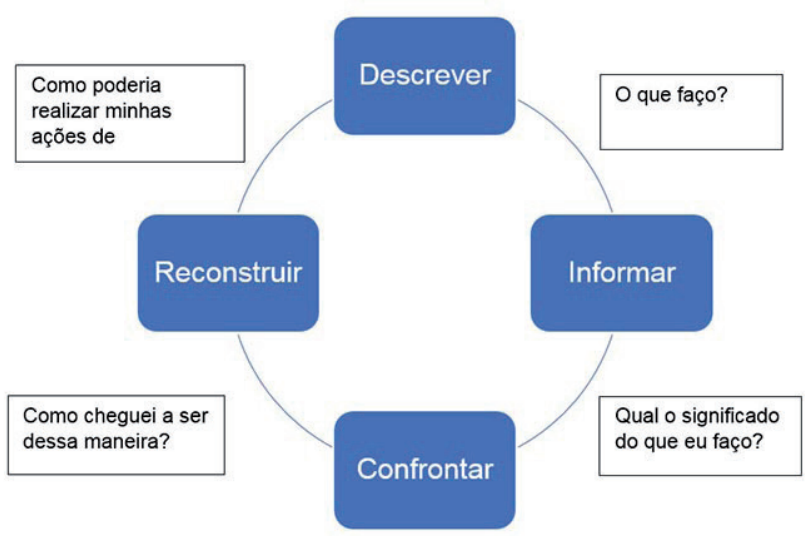

Fonte: Produzido com base em Liberali (2015)

Nessas sessões, realizadas por meio da videoformação, os professores puderam assistir, visualizar as suas ações concretas e as teorias que embasam essas ações, possibilitando o confronto do que dizem com a prática real. Esse movimento fez com que eles refletissem em conjunto, colaborativamente, construindo possibilidades e contribuindo com suas práticas para o seu contexto de atuação.

No Quadro 1, apresentamos algumas perguntas realizadas durante as sessões reflexivas. Essas questões deram movimentos ao processo formativo e possibilitaram a identificação, compreensão das interações e classificação das mediações analisadas nesta investigação, as questões foram elaboradas com base nas ações de descrever, informar, confrontar e reconstruir, segundo Ibiapina (2008).

\section{QUADRO 1 - AÇÕES DE REFLEXÃO}

\begin{tabular}{|c|c|}
\hline AÇÕES & PERGUNTAS \\
\hline 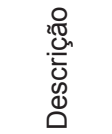 & $\begin{array}{l}\text { Qual Turma/ } n^{\circ} \text { de alunos / série Escola? Qual assunto } \\
\text { trabalhado? Qual o objetivo das Atividades desenvolvi- } \\
\text { das? E a organização e condução da aula? Como ini- } \\
\text { ciou a aula? Forma de participação dos alunos? }\end{array}$ \\
\hline 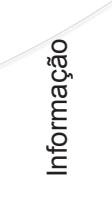 & $\begin{array}{l}\text { Você acha que atingiu seu objetivo? De que maneira? } \\
\text { Que tipo de conhecimento foi trabalhado (conceitual, } \\
\text { procedimental, atitudinal)? Por que fez opção por este } \\
\text { conhecimento? A que concepção ou teoria a sua práti- } \\
\text { ca está relacionada? Por quê? Qual foi o seu papel na } \\
\text { aula e nas atividades? Por quê? Houve interações? E } \\
\text { colaboração? Você refletiu sobre a aula dada? Como? }\end{array}$ \\
\hline 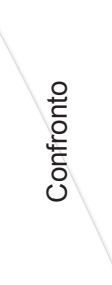 & $\begin{array}{l}\text { De que maneira a aula contribuiu para a formação dos } \\
\text { alunos? Qual a importância do conhecimento trabalha- } \\
\text { do para transformar a realidade do aluno? De que ma- } \\
\text { neira o aluno pode utilizar o conhecimento trabalhado } \\
\text { na sua prática diária? Quais as vantagens e desvanta- } \\
\text { gens de sua aula? Que teorias contribuíram para você } \\
\text { elaborar a aula? Como você fez a articulação entre } \\
\text { teoria e prática? Sua prática foi colaborativa? Por quê? } \\
\text { Sua prática foi reflexiva? Por quê? }\end{array}$ \\
\hline 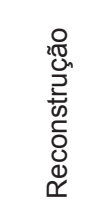 & $\begin{array}{l}\text { O que você faria diferente em sua aula? O que deve } \\
\text { ser feito para mudar? Que relação existe entre a sua } \\
\text { ação de ensinar hoje e a realizada antes da sessão? O } \\
\text { que você faria para articular teoria e prática nas suas } \\
\text { próximas aulas? O que você faria diferente para que } \\
\text { a colaboração e a reflexão façam parte de sua prática } \\
\text { cotidiana? }\end{array}$ \\
\hline
\end{tabular}

Fonte: Ibiapina (2008, p. 83).

O material produzido nas sessões reflexivas foi essencial para caracterizar os níveis de reflexividade e, a partir disso, classificar as mediações ocorridas durante o processo de formação continuada. Compreendemos que o uso do recurso videoformação em ações formativas que envolvem a prática docente possibilita a reflexão crítica e a colaboração em contextos de formação continuada.

\section{3 - ANÁLISE DAS INTERAÇÕES E DAS MEDIAÇÕES DOS PARTICIPANTES}

Com o propósito de analisar e compreender a forma como ocorreram as interações e as mediações e como elas contribuíram para o desenvolvimento profissional dos participantes da proposta de formação continuada, tomamos como referência dois eixos temáticos, sendo eles, colaboração e medição.

Nas sessões colaborativas, em que ocorreram momentos de estudos, discussão e planejamentos de aula, houve situações que se configuraram momentos 
que podem ser considerados de colaboração. Nesses momentos, destacamos diferenças particularidades que entendemos permear ações de dividir, ajudar e colaborar em um contexto educativo. Essas ações, no desenvolvimento da pesquisa, constituíram o eixo temático colaboração, construído com base nas falas dos participes, produzidas nesses encontros.

\section{QUADRO 2 - EIXO TEMÁTICO I}

\begin{tabular}{|c|c|c|}
\hline \multicolumn{3}{|c|}{ COLABORAÇÃO } \\
\hline & $\begin{array}{l}\text { Categoria } \\
\text { Analítica }\end{array}$ & Indicadores Interpretativos \\
\hline $\begin{array}{l}\text { Sessões } \\
\text { colaborativas } \\
\text { e } \\
\text { Entrevista } \\
\text { coletiva }\end{array}$ & $\begin{array}{l}\text { Interações } \\
\text { Colaborativas }\end{array}$ & $\begin{array}{l}\text { Colaborar entre os } \\
\text { participantes; } \\
\text {-Apoio mútuo; } \\
\text {-Objetivo comum; } \\
\text {-Ações não hierárquicas; } \\
\text { - Falas que indicam } \\
\text { colaboração nas ideias e } \\
\text { no agir; } \\
\text { - Expressões utilizadas: } \\
\text { nós, o grupo, todos, juntos. }\end{array}$ \\
\hline
\end{tabular}

Fonte: produzido pela autora baseado em Ibiapina (2008), Magalhães (2011) e outros

Para fazer as análises referentes ao eixo colaboração, utilizamos, como base, os indicadores que se encontram no Quadro 4 deste trabalho. Assim, objetivando compreender como ocorreu a colaboração no contexto em que realizamos este estudo e de que forma contribuiu para o desenvolvimento profissional dos dois professores participantes, analisamos as falas dos partícipes, considerando, como referência, pronomes pessoais e expressões relacionadas ao ato de colaborar.

Nas sessões que consideramos reflexivas, buscamos momentos que levassem os professores a refletir criticamente sobre as suas ações. Nesses encontros, foi possível resgatar a forma como os participantes desenvolviam as suas aulas e como puderam desenvolvê-las a partir da elaboração em grupo, em que, por meio das aulas gravadas, foram realizadas as ações de reflexão.

Para identificar as mediações nessas sessões, buscamos algumas leituras e optamos em usar os níveis de reflexão de Albuquerque (2008), Souza (2012) e Liberali (1999), entre outras e, com isso, foi possível classificar os tipos de mediações, como sendo: mediação técnica, mediação prática e mediação crítica.
No intuito de um melhor esclarecimento sobre a reflexão que nos referimos, discorremos sobre os pressupostos epistemológicos que orientam os três tipos de reflexão que abordamos neste estudo: técnica, prática e crítica.

Partindo do pressuposto que pretendemos identificar as interações e as mediações presentes na formação continuada de professores, optamos em classificá-las, de acordo com os níveis de reflexão. Nesse movimento, encontramos autores como Liberali (2015), Magalhães (2004; 2009), Ibiapina (2008), Dewey (1933), Schön (1992), Kemmis (1999), Zeichner (1993) e Freire (1986), que fundamentaram o estudo sobre a temática reflexão e, consequentemente, os seus níveis. Buscando os elementos epistemológicos que encaminham a esses tipos de reflexão, teceremos comentários sobre cada um deles, começando pela reflexão técnica.

A reflexão técnica caracteriza-se pelo professor que enfrenta as questões de sua prática aplicando rigorosamente técnicas científicas, tornando a sua atividade instrumental. Nesse caso, a teoria surge como fonte para transformar a ação. Liberali (2015) afirma que esse tipo de reflexão leva os professores a usar novas abordagens sem avaliar práticas anteriores.

A reflexão prática caracteriza-se essencialmente pela tentativa de encontrar soluções para a prática na prática. A reflexão do professor nesse nível volta-se para os problemas da ação, baseando-se no senso comum. Para Liberali (2015, p. 28), " [...] interessa aqui o conhecimento que facilita o entendimento e o alcance do entendimento com outros".

A reflexão, denominada crítica, envolve tanto a reflexão técnica quanto a prática, porém diverge dessas modalidades por possuir em sua essência a racionalidade dialética e, principalmente, por considerar além da sala de aula, levando em conta os efeitos do contexto social onde ocorre a ação educativa.

Apoiada nas ideias de Smyth (1992), Liberali (2004b) esclarece que a atividade da reflexão crítica se desenvolve, a partir da proposta de quatro formas de ação: descrever, informar, confrontar e reconstruir, as quais foram descritas no tópico anterior. Essas ações, no desenvolvimento do estudo, constituíram o eixo temático Mediação, construído com base nas falas dos partícipes, produzidas durante as sessões 
denominadas reflexivas. No Quadro 3, apresentamos como organizamos o eixo e os indicadores interpretativos, para realizar a análise dos tipos de mediação neste trabalho.

\begin{tabular}{|c|c|c|c|}
\hline \multicolumn{4}{|c|}{ MEDIAÇÃO } \\
\hline \multirow{5}{*}{$\begin{array}{l}\text { Sessões } \\
\text { reflexivas }\end{array}$} & \multicolumn{2}{|c|}{ Categorias Analíticas } & $\begin{array}{l}\text { Indicadores } \\
\text { Interpretativos }\end{array}$ \\
\hline & Técnica & $\begin{array}{l}\text { Ações de } \\
\text { informar }\end{array}$ & $\begin{array}{l}\text { - Uso de métodos e } \\
\text { técnicas de ensino; } \\
\text { - Aula expositiva; } \\
\text { - Explicações teóricas; } \\
\text { - Dependências de } \\
\text { estratégias; } \\
\text { - Alcance dos objetivos } \\
\text { estabelecidos por } \\
\text { outros. }\end{array}$ \\
\hline & & $\begin{array}{l}\text { Ações de } \\
\text { descrever }\end{array}$ & $\begin{array}{l}\text { - Soluções para prática } \\
\text { na prática; } \\
\text { - Busca de soluções } \\
\text { imediatas; } \\
\text { - Discorre sobre a } \\
\text { prática; }\end{array}$ \\
\hline & Prática & & $\begin{array}{l}\text { pessoais; } \\
\text { - Senso comum; } \\
\text { - Resolve problemas } \\
\text { da ação que não são } \\
\text { passíveis de serem } \\
\text { resolvidos apenas de } \\
\text { forma instrumental. }\end{array}$ \\
\hline & Critica & $\begin{array}{l}\text { Ações de } \\
\text { confrontar e } \\
\text { reconstruir }\end{array}$ & $\begin{array}{l}\text { - Visão crítica } \\
\text { - Questiona a própria } \\
\text { prática; } \\
\text { - Valorização de } \\
\text { critérios. morais } \\
\text { - Ênfase na autonomia }\end{array}$ \\
\hline
\end{tabular}

QUADRO 3 - EIXO TEMÁTICO II

Fonte: Elaborado pela pesquisadora com base em Smyth (1992) e Liberali (2015) e outros.

$\mathrm{Na}$ intenção de compreender como as interações e as mediações contribuíram para o desenvolvimento profissional de dois professores participantes da proposta de formação continuada, consideramos os dois eixos temáticos descritos anteriormente, os quais auxiliaram na busca pela compreensão, identificação e classificação dos tipos de mediações.

Extraímos excertos das transcrições, que revelam como se deu a colaboração, as interações, as mediações e como o grupo foi se constituindo. Partimos do princípio que os elementos essenciais para colaboração são a comunicação e a interação.

\section{1- AS INTERAÇÕES QUE DERAM MOVIMENTO A COLABORAÇÃO}

Apresentamos, a seguir, alguns relatos e momentos ocorridos durante as sessões realizadas na pesquisa, que revelaram como o grupo foi se constituindo e de que forma a colaboração permeou esses momentos, assim como os professores envolvidos no processo de formação compartilharam vivência e experiência com os seus pares e puderam mostrar a realidade da sala de aula aos colegas ainda em formação.

Durante a leitura das transcrições, compreendemos que um dos momentos iniciais de interação ocorreu quando o grupo discutiu a música de Almir Sater, "Tocando em Frente", logo no segundo encontro. Os participantes tiveram que destacar trechos da música que, de alguma forma, chamaram a atenção. Foi um momento inicial de conhecimento dos integrantes, em que eles puderam conhecerem-se. Na escolha da estrofe "a certeza de que muito pouco eu sei, e nada sei”, a fala de Lorenzo mostra a importância da relação entre os participantes e dos diferentes contextos para partilha de conhecimentos.

Lorenzo: [...] cada um tem uma realidade, isso me fez ver que eu não sei nada, eu tenho que continuar caminhando, tenho que ter a humildade para aprender, para ouvir, para trocar experiências, para aprender com os colegas, com outros professores e a importância de continuar estudando, continuar aprendendo. (SESSÃO 2, 9/2013).

Nesse movimento, o processo de formação ocorre quando os integrantes tomam consciência da importância da contribuição do outro para a sua constituição como pessoa e profissional e conscientiza-os sobre a própria prática. Ibiapina (2012, p.7) afirma que: "Ao observar a prática de outros professores, estamos em processo ao mesmo tempo inter e intraformativo, o que promove desenvolvimento no devir de ser e tornar-se professor crítico".

Diante de um clima de descontração, o grupo foi se envolvendo e compreendendo a dinâmica do trabaIho, principalmente, que eles teriam voz ativa fazendo parte da formação não apenas como espectadores. Ibiapina (2008) esclarece que a colaboração não é 
algo natural, ela precisa ser ensinada e aprendida deliberadamente. Para isso, Celani (2003, p 27) reforça que esse processo é "[...] um trabalho ativo, consciente que pressupõe esforço, vontade e que tem lugar quando condições são criadas para isso".

Na terceira sessão, durante a discussão do texto "A formação do professor investigador na escola e as possibilidades da pesquisa colaborativa: um retrato sem retoques" (GRÍGOLI et al., 2007), podemos identificar as compreensões inicias de colaboração na fala de Lorenzo:

Lorenzo: Mas, pelo menos, eu entendi que a pesquisa colaborativa seria você pesquisar aquilo que tem sido feito, o que pode melhorar e essa pesquisa você coloca em prática, esses resultados colocam-se em prática, um colaborando com o outro, as suas experiências, o que tem vivido, uma forma de melhorar o ensino, porque eu acho que não existe razão maior que professores e acadêmicos se reunirem, se não fosse para melhorar a qualidade do ensino, né?

(SESSÃO 3, 03/2013)

Fica evidente, nessa fala, que, em um trabalho dentro da perspectiva colaborativa, as relações incluam interesses pessoais e sociais, que sejam comuns entre os participantes e que as ações de formações auxiliem os professores e os pesquisadores a valorizar a qualidade do outro, construindo um ambiente de discussão, de autonomia e respeito mútuo, como propõe Bakhtin (2000).

De acordo com Ibiapina (2008), deve-se compreender, primeiramente, qual o significado de colaboração internalizado pelos participantes. Nas discussões provocadas a partir dos textos, a compreensão de colaboração dos participantes partiu sempre do senso comum e começou a ganhar significado a partir das discussões realizadas na sétima sessão, quando trataram das diferenças entre colaborar e cooperar.

Lorenzo: Pelo texto, eu sei que diferencia colaboração e cooperação. [...] Cooperar depende do que você precisa e do que você me pediu. Colaborar é quando eu me preocupo.

Valentina: Cooperar você ajuda e nem se pre- ocupa com os resultados. [...]. Você ajudou a pessoa. Agora, colaborar, você ajuda, você volta para ver os resultados que deu, você se importa. Então, essa é uma diferença.

(SESSÃO 7, 11/2013)

A interação no grupo contribui para uma discussão em que os diferentes sentidos atribuídos ao conceito convergem para um significado social, levando as formulações das palavras e dando início a um processo em que as enunciações são restruturadas. Tal dado aparece na fala de Valentina quando a discussão sobre colaboração foi retomada na oitava sessão:

Valentina: O objetivo maior de estarmos aqui é que cada um tem sua autonomia, então a colaboração... [...] muitos pensam que quando estão cooperando, ele está colaborando e não é. Cooperar é só o processo, e colaborar é você estar antes, durante e depois com a pessoa, você faz parte do processo.

(SESSÃO 8, 11/2013)

Tendo em vista que o enfoque não é o estudo de teorias para serem aplicadas em sala de aula, mas visando à compreensão das condições do trabalho do professor, colaborar não significa cooperar, tampouco participar. Dessa forma, para colaborar com a pesquisa, segundo Ibiapina (2008), é necessário que os participantes tenham voz para descrever e interpretar teorias e práticas, concordar e discordar dos discursos dos seus pares e das teorias vinculadas ao contexto educacional.

A seguir, apresentamos trechos com interações envolvendo Valentina e Lorenzo nas sessões colaborativas realizadas em que conforme a nossa análise pode ser considerada indícios de colaboração.

Ao retornar à análise das sessões no ano de 2014, é possível observar que o grupo discutiu os conteúdos que seriam abordados e foram elaboradas atividades, a partir das necessidades da escola em que Lorenzo atuava. Naquele momento, os participantes iniciaram as ações nas escolas e, para isso, o grupo negociava as atribuições cada um, na sessão 11, as graduandas questionavam qual seria o seu papel na pesquisa:

$\mathrm{G1}$ : $\mathrm{E}$ as formandas entram em quê? 


\section{P1: Transcrição.}

(risos)

Valentina: Boa pergunta! O papel das graduandas é nos auxiliar em tudo.

P2: Ah! Então, eu vou participar da transcrição também?

(SESSÃO 11, 03/2014)

Ibiapina (2008) reitera que o trabalho colaborativo e a negociação de atribuições viabilizam a colaboração entre os partícipes e deve-se criar um clima democrático para enfrentá-lo e geri-lo coletivamente. No diálogo, que segue, os professores tentam negociar o que será trabalhado, há uma tentativa de negociação, mas ainda há indícios de hierarquia na fala de Valentina.

Lorenzo: Eu precisava saber, assim, por que aqui a gente vai definir a turma, né? $E$ o conteúdo ....?

P1: Pode ser um conteúdo que eu já trabalhei agora? Aí eu desenvolvo coisa diferente?

Valentina: [...] O nosso papel vai ser essa questão de ajudar vocês a produzir um material para nós aplicarmos lá. Esse é o nosso papel. [...] Nós vamos produzir, o que nós vamos trabalhar, por exemplo, frações. Daí, nós vamos pesquisar.

(SESSÃO 12, 03/2014)

$\mathrm{Na}$ busca pelo rompimento da hierarquia, os participantes sempre retomam a fala, buscam corrigir os termos usados para que o trabalho possa atingir a colaboração e, nessa mesma sessão, Valentina retoma a fala e reforça a importância das características da colaboração discutidas nas sessões anteriores.

Valentina: Porque para haver a colaboração tem que existir a parceria entre Professor Universitário, Professor da Educação Básica, Mestrandos/ Doutorandos e entre os Licenciandos. Essas interações podem denominar de ciclo de colaboração, pois cada integrante do grupo tem que estar disposto a ouvir o próximo, buscar subsídios para ajudar na reflexão dos pares

(SESSÃO 12, 03/2014)
A fala de Valentina mostra indícios da compreensão do conceito de colaboração, como também demonstra o objetivo comum do grupo. Na fala de Lorenzo, ao relatar sobre o seu trabalho no projeto para o diretor da escola que apoia o seu envolvimento, também fica evidente a colaboração.

Lorenzo: A gente tem esse trabalho lá que ouve todo mundo e cada um tem opinião, essa troca de informação faz que tenhamos uma visão mais para fora da sala de aula.

(SESSÃO 12, 03/2014)

Nesse ambiente de trabalho, o grupo identificava as necessidades para iniciar as ações nas escolas, assim posto, a partir da fala de Lorenzo: "No geral, o que mais dá trabalho para ensinar no sexto ano são as frações" (SESSÃO 12, 03/2014), o grupo iniciou a busca por possibilidades de ensino desse conteúdo.

As sessões que reuniam o grupo geral tornaram-se momentos de partilha de experiências e a compreensão de colaboração foram aparecendo na fala dos participantes que mostraram preocupação em tornar o trabalho colaborativo. Podemos observar essa percepção na fala de Valentina ao relatar sobre o planejamento das atividades sobre frações para os demais subgrupos.

Valentina: Esse trabalho é feito em conjunto para que haja a colaboração, pois a colaboração é marcada pela ajuda mútua e, sem a ajuda, o grupo dificilmente se constitui como colaborativo. E se já temos a ajuda mútua, fica explícito a questão da confiança estabelecida pelo diálogo. E, nesse trabalho gostei muito da iniciativa das graduandas, em colaborar na construção das peças do Tangran de EVA.

(SESSÃO 14, 03/14)

As interações dentro do grupo provocaram descobertas que sugiram pela dinâmica realizada na elaboração dos planejamentos em conjunto, assim como os momentos de discussão das atividades provocaram os partícipes e levaram-nos a questionar os seus próprios conhecimentos como também compreenderem a importância do outro na construção de conhecimen- 
to. Valentina reconheceu a importância da discussão em grupo das atividades realizadas em sala durante a elaboração do planejamento sobre noções de frações, para o sexto ano do Ensino Fundamental.

Valentina: Quantos triângulos menores cabem no triângulo médio? Na verdade, no médio cabem duas vezes. Bem, deixa eu pensar.

Lorenzo: Quantos menores cabem no médio?

Valentina: É?

Lorenzo: Metade.

Valentina: Deixa eu ver como é aqui... É verdade, metade mesmo. Eles vão sobrepor, bem se é metade quer dizer que a área desse triângulo (médio) é a mesma do quadrado e a mesma do paralelogramo. Interessante, né?

Lorenzo: Bacana, né? O tempo vai passando e nós vamos trabalhando a forma normal, comum, e não vemos essas coisas bacanas.

Valentina: Isso tudo é tempo. Quase não temos tempo. Essa atividade da garrafa, algo simples com material descartável, mas eu, enquanto professora, nunca trabalhei com essas atividades, só fui pensar agora. Eu já tinha trabalhado com o Tangram, mas só montando figuras. Não havia sentido para mim ficar montando essas figurinhas, tais como: gatinha, coelhinho, [...].

Lorenzo: Qual a relação?

Valentina: Não tinha, e eu queria uma relação com a Matemática.

(SESSÃO 15, 04/2014)

Na concepção de Sawyer (2003, p. 82): "Colaboração é a criação compartilhada e a descoberta de dois ou mais indivíduos com habilidades complementares interagindo para criar um entendimento partilhado que nenhum deles tinha possuído antes ou poderia ter conhecido por si só".

Este trabalho possibilitou-nos entender que, por meio da colaboração, os professores seriam capazes de compreender os sentidos e significados acerca da interação e da colaboração. Essa compreensão, quando realizada em contextos de formação que buscam uma criticidade dos participantes, cria modos de participação que instigam os indivíduos por meio da interação com pares mais experientes.
Neste sentido, Vygotsky (2001) afirma que a atividade humana, ou seja, o trabalho docente, é responsável pela ampliação de funções psicológicas ainda não inteiramente solidificadas no processo de desenvolvimento. Dentro dessa perspectiva, o professor medeia a produção partilhada, pois considera que o par menos experiente é capaz de fazer em colaboração, conseguirá fazer posteriormente sozinho. E é exatamente essa condição que possibilita o desenvolvimento do sujeito.

No ano de 2015 , as sessões colaborativas foram retomadas em março e a dinâmica continuava a mesma. Primeiramente, o grupo levantava as necessidades dos professores que estavam em sala de aula e, depois, buscava atividades para serem desenvolvidas.

Naquele momento, o grupo já estava mais avançado em relação à compreensão da pesquisa colaborativa, ou seja, todos já sabiam os seus papéis, mas o momento era outro e as necessidades ficaram mais refinadas. O grupo ganhou mais autonomia nas suas escolhas e mais poder de decisão em conjunto. Assim, a colaboração mostrou-se nesses momentos de discussão sobre o conteúdo a ser trabalhado, na organização do trabalho a ser desenvolvido em sala de aula, na negociação diante das condições que a escola oferece como se relata nas sessões 23 e 24 .

Valentina: Então, eu estou no oitavo ano, o Lorenzo e o P3.

Pesquisadora: Todos vocês têm oitavo ano?

Lorenzo: Exato. Fica uma coisa só para todos. É bom, porque tem como nós discutirmos.

[...]

Valentina: Então, nós vamos pensar juntos, o que nós vamos trabalhar nesses oitavos em relação à geometria. Podemos pensar algo para o dia 30. Eu pensei em trabalhar aqueles conceitos iniciais e construir com eles, com palitinhos de churrasco e bolinhas de isopor. Eles poderiam fazer várias figuras tridimensionais e, depois, passaríamos uma atividade para eles explorarem, ou seja, eles mesmos podem responder a partir dos nossos questionamentos. E, a partir daí, trabalharíamos o conceito. Não sei se vocês estão de acordo com isso? 
Lorenzo: Então, por que no oitavo ano? Porque no segundo bimestre é sistema, cálculo algébrico, polinômios, expressões algébricas, espaço e forma, construção de paralelas, perpendiculares, mediatrizes, segmentos com régua e compasso, congruência de triângulos.

Valentina: Com a construção desses sólidos, com essas bases, nós vamos estar trabalhando com retas [...].

Pesquisadora 1: Já explora vários conceitos.

Valentina: Isso. Eu já tinha olhado essa ementa. P3: Mas, esse material seria usado como uma introdução, porque ali fala régua e compasso.

Lorenzo: Mas, régua e compasso, nós não vamos usar.

P3: Não?

Lorenzo: Não, porque os alunos não têm, não chegou o material, a Prefeitura não mandou esse material, não temos nem régua.

(SESSÕES 23 e 24, 04/2015)

Compreendemos, a partir dessas falas, que a formação continuada colaborativa é possível quando os participantes aceitam aprender uns com os outros, ou seja, aceitam investir no compartilhamento de significados e na análise de suas práticas que criam o desenvolvimento cognitivo e afetivo como uma possibilidade de mudança, conforme defende Charlot (2005), a aprendizagem é cheia do desejo e do envolvimento de professores que estão aprendendo a profissão.

Um dos pontos iniciais da formação é atender a necessidade do professor, pois, a partir dessas necessidades vivenciadas por eles devem surgir as demandas de formação. Assim, quando o participante emite uma necessidade, ele também declara uma ação de mudança, porque ela é sempre justificada.

Atender essas necessidades do professor por meio de uma formação é, para Ibiapina (2008, p. 42), "[...] retraduzir as motivações e os objetivos construídos pelo grupo de professores para construção permanente de seu desenvolvimento profissional". Destacamos um desses momentos, que ocorreu na vigésima sexta sessão.

Valentina: Então, eu gostaria de trabalhar na parte de espaço e forma, com sólidos geométri- cos e figuras planas.

Pesquisadora: Mas, você acha que os alunos têm dificuldades nesse conteúdo?

Valentina: Esses dois conteúdos, tem muitos professores que nem trabalham. Eu mesma fico muito amarrada com os outros blocos, números e operações [...]. Agora, o que o Lorenzo falou no encontro passado é verdade. Eles querem que nós trabalhemos os quatros eixos durante o bimestre [...], então, essa atividade que eu estava pensando vai atender tanto os sólidos geométricos como as figuras planas.

Os indícios de colaboração ficam evidentes nas sessões, o engajamento, a partilha de conhecimentos e a negociação fazem-se presentes nos momentos de planejamentos, pois eles são ricos de experiências e ao aprendermos com o outro transformamo-nos, como afirma Vygotsky (2000). A colaboração vai se constituindo quando o grupo se mostra numa ação conjunta por um objetivo único, como no diálogo da $26^{a}$ sessão.

Valentina: Pensei que hoje podemos conversar, trocar ideias e, na próxima semana, providenciar os materiais. Uma coisa que eu pesquisei e gostei foi a mesma ideia que a G1 trouxe. Estamos bem conectadas.

Todos: (risos)

Lorenzo: Eu acho que nós também estamos bem conectados, porque eu sai de casa pensando justamente nisso. Sabe o que eu pensei, [...] nós podemos fazer a planificação, porque trabalha a figura plana e também espacial. Não é?

(SESSÃO 26, 05/2015)

O processo de colaboração envolve também os conflitos, entretanto é importante criar um clima democrático para gerencia-los de forma criativa. Bakhtin (2002, p. 14) afirma que "[...] a palavra é a arena onde se confrontam os valores sócios contraditórios, e, em qualquer momento de sua existência, é de natureza múltipla, pois nela, na palavra coexistem contradições sócioideológicas".

Destacamos que ao apresentarmos as sessões 
evidenciamos que houve momentos de colaborações, observamos que participantes ao longo das sessões colaborativas foram ampliando a compreensão do conceito de colaboração e fazendo dele parte de suas ações no grupo. No entanto, não podemos afirmar apenas por essas sessões que houve transformação, pois sabemos que elas só podem ser verificadas no contexto de atuação dos partícipes, na sua atividade.

Para isso, apresentaremos a seguir as análises das sessões reflexivas em que os participantes discutiram as ações das aulas, onde relataram a contribuição do trabalho em grupo para o seu contexto. Explicitamos as análises do eixo mediação em que analisamos os níveis de reflexão por meio das ações de descrever, informar, confrontar e reconstituir durante as sessões reflexivas no contexto da formação continuada para professores de Matemática.

\section{2 - AS INTERAÇÕES QUE DERAM MOVIMENTO AOS TIPOS DE MEDIAÇÃO}

Os dados produzidos durantes as sessões reflexivas, possibilitaram que os partícipes fizessem análise de suas aulas, as quais foram desenvolvidas por meio do planejamento elaborado nas sessões colaborativas, em contexto de colaboração, permitindo que todos tivessem oportunidade para expor as suas opiniões. Na visão de Vygotsky (2001), os sujeitos constroem-se na interação com o mundo e na sua relação com os outros e o trabalho colaborativo torna-nos mais fortes, oferecendo condições de resolver problemas mais complexos. Ademais, Bakhtin (1997) afirma que o individual só se realiza se tiver como base o coletivo.

Os fragmentos apresentados na sequência representam os momentos que consideramos mais relevantes de algumas sessões reflexivas em que foram discutidos o desenvolvimento de dois planejamentos e que as falas naquele contexto mediado pela reflexão individual e coletiva, pelas leituras realizadas nas sessões colaborativas permitiram identificar em que níveis de reflexão eles encontravam-se na ocasião e, assim, classificar os tipos de mediação.

Durante as ações de informar, Lorenzo ainda confirmou a ideia de que: "muitos autores defendem que você deve construir os conceitos, mas eu não sou contra, eu sou a favor. Mas, pensei se eu pegar esse material e der para os alunos, eles vão reproduzir". Ao assistir à aula sobre poliedros, Lorenzo informa o porquê agiu dessa forma ao ser questionado por dar a fórmula de Euler pronta.

Lorenzo: Peguei a relação de Euler e expliquei para eles e, na hora da aula prática, eu só dei a fórmula sem os nomes dos poliedros, sempre faltando alguma coisa, aresta ou vértice ou face. Assim, eu acredito que essa foi a construção. Os alunos colocaram em prática os conceitos matemáticos, depois que eles copiaram essa tabela no caderno e preencheram foi que eles montaram os poliedros com o material. Nós colocamos uma mesa ao meio da sala com o material, não tinha nenhuma figura montada, e todos ficaram em volta. Então, eu pedi para cada representante de grupo ir até a mesa e pegar somente a quantidade de material que iriam precisar, exemplificando se vai montar o tetraedro, então vai precisar de $\mathrm{x}$ aresta, e eles discutiam e depois que chegassem a um acordo, pegavam somente o que precisavam.

Evidenciamos que as suas explicações possuem visões teóricas que sustentam as suas ações e os sentidos construídos em sua prática. Ao afirmar: "o livro didático mostra face, aresta e vértice e pergunta o que eles conseguem relacionar. Eu só tive uma turma no ano passado, que conseguiu isso e foi em uma escola particular, em que um aluno conseguiu notar que isso estava relacionado com o nome do poliedro. Mas, no nosso caso, o importante não é a relação, mas os poliedros". (SESSÃO 32, 06/15).

Essas informações possuem compreensões teóricas do que é o objeto de ensino e remetem às teorias de aprendizagens, que fornecem generalizações das ações do professor, como parte de um conjunto de ações que justificam a sua forma de agir e entender o mundo. Segundo Liberali (2015), essas informações permitem ver o particular em relação ao geral. Diante da fala anterior, compreendemos que ocorreu uma mediação prática, pois predominou, nesse momento de interação, a ação de descrever.

Nas sessões que ocorreram a videoformação, identificamos que os participantes retomaram concei- 
tos importantes da sala de aula, enquanto assistiam ao vídeo em que foram levados à compreensão das teorias adotadas. Esse momento contribuiu para "identificar as razões pelas quais os alunos não aprendem e tornar possível a compreensão dos significados construídos no processo de ensino-aprendizagem" (LIBERALI, 2015, p. 74).

Valentina: Para a realidade daquela escola, as atividades relacionadas com o Tangram trouxeram mais resultados do que as atividades sobre capacidade do litro, de quantas vezes cabe.

Lorenzo: Eu acredito que essa prática ajuda nisso, pelo menos, ele visualizar aquilo que está fazendo, por isso que a prova na prática tinha as mesmas questões que elaboramos aqui, lembra, tinha questões de frações equivalentes, tinha soma de frações com denominadores iguais, só que eles simplesmente chegaram a ver essa equivalência, eles fizeram com o Tangram, então o que acontece o Tangram deu mais resultados né, ai eles pegaram as peças do Tangram e associaram quantas vezes, por exemplo, o triângulo menor cabe no quadrado, ai eles representaram com a fração, e foram lá e fizeram no correto, então aqueles que eram, que foi bem pouco, foi justamente por falta de atenção, ou alguma coisinha, mas na sua maioria todos conseguiram visualizar e escrever as frações correspondentes. $E$ ai quando a gente joga só os números, eles às vezes não conseguem interpretar, ele pode ler lá e está óbvio mas não consegue associar. E isso vai do sexto até, se bobear, na graduação.

Lorenzo: Eu trabalhei frações no ano passado, são duas escolas diferentes, de realidades diferentes, mas a gente vê o resultado. Para ter uma ideia, quando eu fiz a avaliação prática, eu fiz duas avalições, uma teórica, onde os alunos fizeram os cálculos normalmente, e a outra prática. A prática valendo de zero a cinco e a menor nota foi 4,5 .
Valentina: No caso do aluno L, ele foi ajudante, mas, na hora de fazer as atividades, ele não conseguia ler e interpretar, e ele, na parte prática, respondia tudo com clareza. Então essas atividades vão ajudou muito na interpretação dos alunos.

(SESSÃO 32, 06/15).

Nas discussões realizadas nessa sessão, evidenciamos o uso frequente da palavra prática pelos participantes. Entendemos que a forma de trabalho usual que adotavam em suas aulas não envolvia um planejamento com materiais didáticos ou manipuláveis. $\mathrm{Na}$ fala de Lorenzo fica evidente que as suas aulas valorizam os conteúdos matemáticos sem se preocupar com as questões pedagógicas do conteúdo. Ao relatar o uso da prova prática, em que avaliou a produção dos alunos, no momento que manipulavam os materiais didáticos para resolver as atividades propostas, demonstrou que a sua organização de aula não era realizada e pareceu-nos produtiva, principalmente, por levá-lo a avaliar os seus alunos de outra forma, tendo um resultado mais satisfatório de que o que havia sendo realizado.

As sessões reflexivas, além de permitir que os participantes compreendessem os significados de suas práticas, foram importantes também para levá-los a uma reflexão mais crítica, estimulando-os a olhar mais adiante, deixando a análise pontual e relacionando o contexto da aula com o uso social dos conhecimentos construídos naquelas aulas, como podemos observar no fragmento a seguir da mesma sessão anterior.

Lorenzo: Fração é um conteúdo relativamente difícil para eles, porque quando a gente passa no quadro, ele vê ali aquilo que representa fração, mas, na verdade, ele não sabe o que é, ele não sabe fazer cálculo, porque a gente passa para ele o algoritmo, a forma de calcular. Então, quando você coloca lá $1 / 3$, ele fala um três e não sabe associar isso a quantidade de coisas que eles conhecem e com o uso dos materiais, a gente conseguiu mostrar isso a eles, que $1 / 3$ pode ser qualquer valor independente do contexto, você tira um terço de quê? Isso, eles conseguiram compreender, o número com a ideia da quanti- 
dade. E eles conseguiram associar, por isso, eu acho que deu resultado, e quando a gente coloca só números, eles ficam limitados, e uma coisa que você conhece é mais fácil de resolver.

Ao compreendermos que as situações de conflitos são consideradas centrais para promover a reflexão crítica e o aprofundamento de questões problemáticas, buscamos durante as sessões reflexivas criar momentos que possibilitassem aos professores notarem acerca das consequências de suas ações, provocando o confronto para, consequentemente, a reconstrução de suas práticas. Neste sentido, Lorenzo ao ser questionado sobre como as teorias contribuíram para aula, faz a seguinte afirmação.

Lorenzo: Quando eu comecei a estudar esses autores, muitas coisas que eles falavam, eu concordava. Por meio dessas teorias, nós vamos encontrando caminhos para fazer. $E$ a parte de reflexão para mim foi fundamental - fazer o planejamento, aplicar, refletir, retomar, mudar, se houver necessidade - e sempre há necessidade, porque pode mudar a turma no próximo ano, para ter um bom resultado. Então, as teorias me ajudaram nesse sentido.

A proposta de formação continuada desenvolvida por meio da pesquisa colaborativa ampliou as possibilidades de os professores conhecerem significados internalizados, como, por exemplo, a colaboração, a fim de confrontá-los e reconstruí-los durante o compartilhamento de significados no grupo, assim como as sessões reflexivas que permitiram a tomada de consciência, pois compreenderam que colaborar vai além do fazer junto, do coletivo, de ideias já construídas. Assim sendo, firmou-se a possibilidade de reorientação de conceitos sobre as práticas que adotam em suas aulas. Dessa forma, ao ser questionado se sua prática foi colaborativa e reflexiva e porque, Lorenzo afirmou:

Lorenzo: Eu recebo uma ajuda grande, se não fosse o trabalho do projeto, eu não teria feito isso assim. Eu estaria lá ensinando da forma usual. [...]. Quando nós sentamos para conversar e vimos o que poderia fazer e como poderia fazer, daí eu vi que realmente um planejamento é o que nós podemos fazer sempre, independente do projeto, sentar e pensar, como eu vou fazer? E daí fazer de uma forma diferenciada para despertar o interesse do aluno que foi o que nós fizemos e me fez refletir e ter uma cobrança em mim, porque como eu tenho muitas aulas, eu quero fazer e não tenho tempo. É claro que eu posso fazer na escola com outros professores de Matemática, mas se não tem tempo, você nem vê os outros professores, nem conversa. A relação que eu consigo fazer é essa que fazemos aqui, de sentar, pesquisar, se interessar quanto ao planejamento, ir na escola, aplicar e, depois, pensar, parar e ver o que deu certo ou não, se não deu o que pode melhorar, fazer aquela retomada que nós fizemos aqui.

A sua reflexão mostra-se limitada às paredes da escola, contexto do seu trabalho, e às necessidades funcionais, entendemos que o trabalho nessa perspectiva da mudança envolve a compreensão de que o real e o ideal estão interligados, com isso, é importante conhecer o meio, pois a ação que transforma envolve o querer, notamos na fala de Lorenzo uma consciência de que mudanças são possíveis, quando ele afirma:

Lorenzo: Apesar dos resultados terem sido bons, sempre podemos ter resultado melhor, sempre. [...] Apesar do tangran ter sido muito bom, tem muito [...] o tangran são várias peças e por ter muitas peças havia muitas perguntas relacionadas a cada peça e poderia ter muito mais, porque é uma coisa muito rica. Então, naquele questionário que elaboramos, tinha várias perguntas relacionadas a cada peça. Isso prolongou o tempo da atividade. Sendo assim, acho que poderia ter sido feito em mais aulas. Ficaria menos [...], porque você lidar com crianças durante um tempo, pode ser o tempo que for, ela fica ansiosa então [...] eu mudaria isso aí. [...] A do outro planejamento, eu faria alguma coisa que todos tivessem condições de manusear. Teria feito algum jeito, se desse, não sei.. separaria a turma em grupo maiores e daria para dividir aquele material, porque manuseando o 
resultado é melhor.

[...]

Eu acho que saindo um pouco da sala de aula, ajudaria bastante, mas não para ir para o laboratório de informática. Não que eu seja contra a tecnologia, eu acho excelente, mas eu acho que nós não temos recurso suficiente para todos os alunos. Mas, eu sairia um pouco da sala de aula, mas como tudo tem que ser tão bem programado, fica difícil, e, às vezes, naquele dia que você programou, acaba que não dá para você ir, porque você já está atrasado ou adiantado, mas eu acredito que sair da sala de aula motiva os alunos. Dar aula em outro lugar, numa quadra, uma grama, apesar que nem grama tem lá, mas só de sair da sala de aula, os alunos já saem... [..] porque eu acho o seguinte, qualquer coisa que você faça, que tire eles dali (sala de aula) já é bom, já motiva, tudo que é rotina cansa.

Assim, refletir implica um aprendizado duplo e fluido, que é exercido tanto do coletivo ao individual, quanto do individual ao coletivo, pois, nessa dialética, o indivíduo reflete, torna-se consciente e transforma as condições de existência e desenvolve-se profissionalmente (IBIAPINA, 2008).

Nas falas de Lorenzo, apresentadas anteriormente, identificamos indícios de uma mediação crítica, pois predominaram, nas interações, as ações de confrontar, em que os professores discutiram e refletiram sobre as suas ações durante a participação do projeto em relação às práticas que vinham realizando, antes do trabalho nessa proposta de formação continuada.

A transformação precisa de ação e a reconstrução baseia-se nesse pressuposto. Conforme afirma Liberali (2015), compreendemos que as interações proporcionaram momentos de reflexão crítica e vimos indícios de transformações ao identificar ideias e propostas para novas ações que apareceram nas enunciações, assim entendemos que, para reconstituir, é preciso pensar em novas possibilidades de fazer, indicar outros rumos, novos caminhos, propor novas ações.

Lorenzo: Estratégias para refletir é isso que estamos fazendo aqui, o vídeo que nós assistimos. Outras para refletir? Tem o próprio resultado do teste que fizemos. Eu acho que eu poderia fazer um próprio questionário com eles, porque aquele que trabalhamos avalia só o que eles aprenderam. De repente, para saber o que eles acharam, se viram diferença, houve motivação, para saber deles, né? Porque, às vezes, estamos aqui empolgados achando que foi bom e eles, não. Então, no questionário que nós fizemos, eu mudaria, eu colocaria outras questões para saber a opinião deles.

[...]

Para as próximas aulas, vamos precisar de alguma coisa prática, tem que ser alguma coisa que eles possam manusear, de repente, alguma coisa que nós possamos sair da sala também. Porque aí eles estariam mais motivados e ainda teria alguma coisa prática. Eu penso no sétimo, eles medirem área, calcularem nos muros, veem quando é necessário...

Nessas falas, identificamos a mediação crítica, pois, nessas sessões, predominaram as interações e as ações de reconstruir. O dispositivo mediador, videoformação, possibilitou aos participantes uma reflexão crítica do seu pensar e do seu agir, pois, conforme propõem os autores Freire (1996; 2005) e Giroux (1997), os professores que refletem criticamente entendem e são entendidos como agentes transformadores da realidade em que atuam.

Diante das falas, evidenciamos que a proposta de formação continuada colaborou com os participantes quando proporcionou, por meio de algumas ferramentas metodológicas, o desenvolvimento profissional, ou melhor, quando eles planejaram as aulas, desenvolveram-nas e refletiram sobre essas ações e realizaram sessões colaborativas e reflexivas, além de videogravações. Com isso, foram ampliadas as possibilidades de os professores conhecerem formalmente significados internalizados e poder confrontá-los e reconstruí-los.

Essa análise, por meio dos eixos colaboração e mediação, permitiu compreender como os participantes avaliaram as suas práticas colaborativamente, bem como as mudanças nas ações deles no contexto escolar, as quais proporcionaram novas práticas, assim como as necessidades formativas, as condições 
de trabalho dos professores e as possibilidades que podem ser realizadas diante dessas situações.

A proposta de formação continuada realizada na perspectiva da colaboração, utilizando a pesquisa colaborativa e seus instrumentos mostraram-se como possibilidade de formação e de pesquisa, a qual propiciou coprodução de saberes, a viabilidade de reflexão crítica, de colaboração, partindo das necessidades dos participantes e, principalmente, contribuindo para o seu desenvolvimento profissional.

\section{4 - CONSIDERAÇÕES FINAIS}

No desenvolvimento desta pesquisa, buscamos investigar as interações e as mediações que ocorreram em uma proposta de formação continuada desenvolvida por meio da metodologia da pesquisa colaborativa para o desenvolvimento profissional de professores de Matemática.

A discussão que realizamos sobre formação continuada foi fundamental para conhecermos de onde viemos e onde estamos em termos teóricos para, a partir dessa premissa, visualizarmos para onde iremos nesse campo de estudos e em nossas atividades. A proposta de formação continuada desenvolvida por meio da metodologia da pesquisa colaborativa mostrou-se uma possibilidade propiciadora de desenvolvimento profissional, pois, por meio das sessões realizadas, consideramos colaborativas e reflexivas, que criaram espaços para promover reflexão crítica de natureza colaborativa entre os participantes.

Nas análises, durante as sessões do grupo, vimos que tanto Valentina quanto Lorenzo socializaram conhecimentos e ampliaram o sentido e os significados de suas práticas. Esse movimento permitiu visualizar, nas análises, possibilidades de reflexões de suas práticas, como, por exemplo, Lorenzo ao experimentar outras formas de realização e de desenvolvimento de plano aula em suas salas.

O estudo que desenvolvemos alcançou os objetivos propostos e entendemos que validamos possibilidades de reflexão crítica e colaboração em contextos de formação continuada, por meio das relações, identificamos e classificamos os tipos de mediações, os quais Valentina e Lorenzo encontravam-se naquele momento da investigação. Nessa busca, encontramos, por meio da teoria, que a colaboração e a mediação foram dois elementos importantes e propiciadores do desenvolvimento.

As análises mostraram a importância não apenas do conhecimento específico do conteúdo, mas também pedagógico do conteúdo de Matemática. Notamos que houve mais conhecimentos e experiências didáticas que matemáticas, pois os conceitos matemáticos trabalhados eram de domínio conceitual dos participantes, assim as discussões ocorreram mais em torno das situações didáticas, ou seja, sobre como tornar o conceito compreensível para os alunos e, para isso, o grupo optou por utilizar materiais didáticos manipuláveis para que os alunos construíssem os conceitos abordados, sendo esses momentos de grande aprendizagem para os participantes, principalmente para Lorenzo que não tinha essa prática em suas aulas, principalmente, da "avaliação prática", assim denominada por ele.

Essa proposta de formação continuada deu oportunidade aos participantes da pesquisa, que eram professores atuantes na Educação Básica, poder compartilhar os seus conhecimentos e experiências com futuros professores participantes do projeto. Eles, além disso, também com os seus conhecimentos e a euforia de graduandos, puderam sentir a realidade da sala, principalmente, quando organizaram e pensaram em detalhes as ações a serem desenvolvidas e que nem sempre ocorreram como esperavam.

Embora o projeto OBEDUC no núcleo UFMS tenha apresentado limitações no que concerne à análise do desenvolvimento profissional dos participantes, pois nos limitamos apenas ao contexto da formação e não à atividade docente, o trabalho possibilitou constituir elementos teórico-metodológicos que viabilizaram apontar fatores que propiciaram o DP.

Entretanto, sinalizamos a possibilidade para trabalhos futuros que se propuserem a investigar o desenvolvimento profissional, a partir deste referencial teórico-metodológico, analisem a partir da atividade de seus participantes. Fica, assim, o convite para novas pesquisas, pois o caminho que percorremos não acaba com estas considerações.

Esperamos que este trabalho a partir de seus resultados possa ser disseminado por outros estados, contribuindo com a formação continuada de pro- 
fessores, sempre visando à melhoria da qualidade do ensino aprendizagem de Matemática dos alunos no Mato Grosso do Sul, principalmente para o desenvolvimento profissional de professores de Matemática, como também para as políticas públicas de formação continuada de professores de Matemática da rede pública de ensino.

\section{REFERÊNCIAS}

ALBUQUERQUE, M. Reflexão crítica e colaborativa: articulação teoria e prática no desenvolvimento da atividade docente. $141 \mathrm{f}$. Dissertação (Mestrado) Universidade Federal do Piauí, Teresina, 2008.

BAKHTIN, M. M. Estética da criação verbal. São Paulo: Martins Fontes, 2000.

BAKHTIN, M. M. Estética da criação verbal. São Paulo: Martins Fontes, 2006.

CELANI, M. A. A. Um programa de formação continua. In: CELANI, M. A. A. (Org.). Professores e formadores em mudança: relato de um processo de reflexão e transformação da pratica docente. Campinas, São Paulo: Mercado das letras, 2003, p. 19-36.

DESGAGNÉ, S. O conceito de pesquisa colaborativa: a ideia de uma aproximação entre pesquisadores universitários e professores práticos. Revista Educação em Questão, Natal, v. 29, n. 15, p. 7-32, mai/ ago. 2007.

IBIAPINA, I. M. L. de M. Pesquisa colaborativa: investigação, formação e produção de conhecimentos. Brasília: Liber Livros, 2008.

IMBERNÓN, Francisco. Formação continuada de professores. Tradução Juliana dos Santos Padilha. Porto Alegre, 2010. 120 p.

IMBERNÓN, F. La formación y desarrollo profesional del profesorado: hacia una nueva cultura profesional. Barcelona: Graó, 2009.

KEMMIS, S. Critical reflection. In: WINDEEN, M; ANDREWS, I. Staff development for school improvement. Philadelphia, USA: Falmer Press, 1999. p. 73-90.
LEONTIEV. A. N. O desenvolvimento do psiquismo. São Paulo: Moraes, 1978.

LIBERALI. F. C. O diário com ferramenta para a reflexão crítica. 166 f. Tese (Doutorado) - Pontifícia Universidade Católica de São Paulo. 1999.

Formação critica de educadores: questões fundamentais. 3. ed. Coleção: Novas Perspectivas em Linguistica Aplicada v. 8. Campinas, SP: Pontes Editores, 2015.

MAGALHÃES, M. C. C. Pesquisa crítica de colaboração em projetos de formação contínua em contextos escolares: colaboração na pesquisa e na ação. In: BALDI, E. M.; FERREIRA, M. S.; PAIVA, M. (Org.) Epistemologia das ciências da educação. Natal: Ed. UFRN, 2009. p. 227-243.

MAGALHÃES, M. C. C. Sessão reflexiva como espaço de negociação entre professores e pesquisador externo. IN: FIDALGO, Sueli Salles; SHIMOURA, Alzira da Silva. Pesquisa crítica de colaboração: um percurso na formação docente. São Paulo: Ductor, 2004. Maria Cecília Camargo; OLIVEIRA, Wellington. A colaboração crítica como uma categoria de análise da atividade docente. In: MAGALHÃES, Maria Cecília Camargo; FIDALGO, Sueli Salles. (Orgs.) Questões de método e de linguagem na formação docente. Campinas, SP: Mercado de Letras, 2011.

SOUZA. J. Possibilidades de reflexão crítica e colaboração em contextos de formação continuada: para além do discurso. 133 f. Universidade Federal do Piauí, Teresina, 2012.

VIGOTSKI, L. S. A formação social da mente. São Paulo: Martins Fontes, 2000.

L. S. A construção do pensamento e da linguagem. São Paulo: Martins Fontes, 2001.

ZEICHNER, K. Formando professores reflexivos para uma educação centrada no aprendiz: possibilidades e contradições. In: ESTEBAN, M. T.; ZACCUR, E (Orgs.). Professora pesquisadora: uma práxis em construção. Rio de Janeiro: DP \& A, 1997. 